\title{
NASA's Pursuit of Low-Noise Propulsion for Low-Boom Commercial Supersonic Vehicles
}

\author{
James Bridges, Clifford A. Brown, Jonathan Seidel \\ NASA Glenn Research Center
}

AIAA SciTech 08 January 2018

Supported by

NASA Advanced Air Vehicles Program/Commercial Supersonic Technology Project And by many, many researchers working with NASA on supersonic aircraft noise. 


\section{Airport Noise-A Commercial Supersonics Challenge}

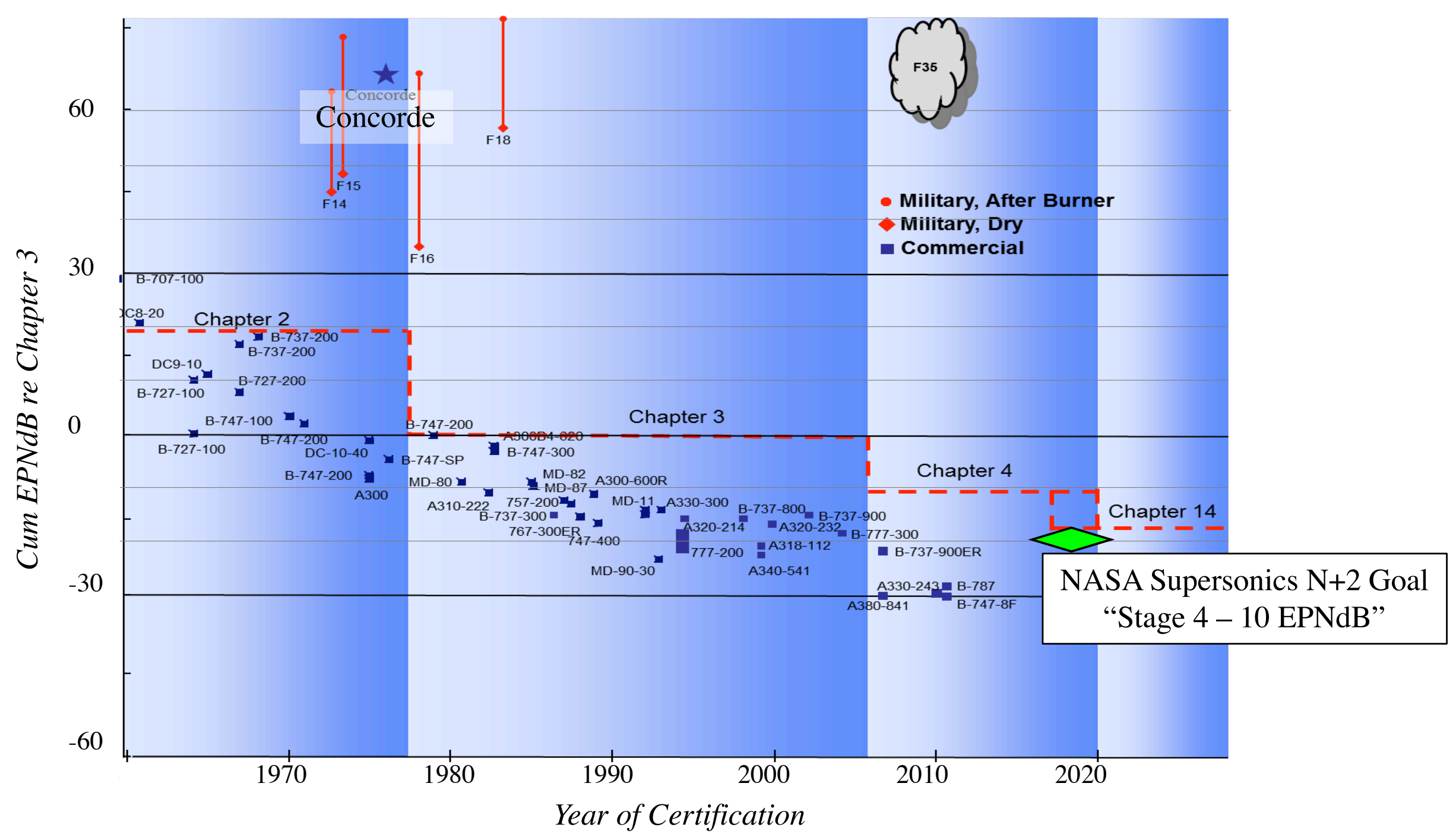

For Lockheed 1044 aircraft, Stage $4-10$ EPNdB equates to 92.7 EPNdB at Lateral observer. This is our Noise Goal. 
NASA's Supersonic Low Noise Propulsion Technical Challenge

Exit Criteria: Creating design tools and innovative concepts for integrated supersonic propulsion systems with noise levels of 10 EPNdB less than FAR 36 Stage 4 demonstrated in ground test.

- Built on years of jet noise reduction exploration, prediction tool development

- Based on Lockheed-Martin 1044 airframe (aero performance, sonic boom) - 70 PAX, 145-tonne, low boom, 1.6 $\mathrm{M}_{\text {cruise }}$

- Explored propulsion cycle/nozzles; focused on installed jet exhaust noise

- Validated designs in scaled model rig test with simulated planform
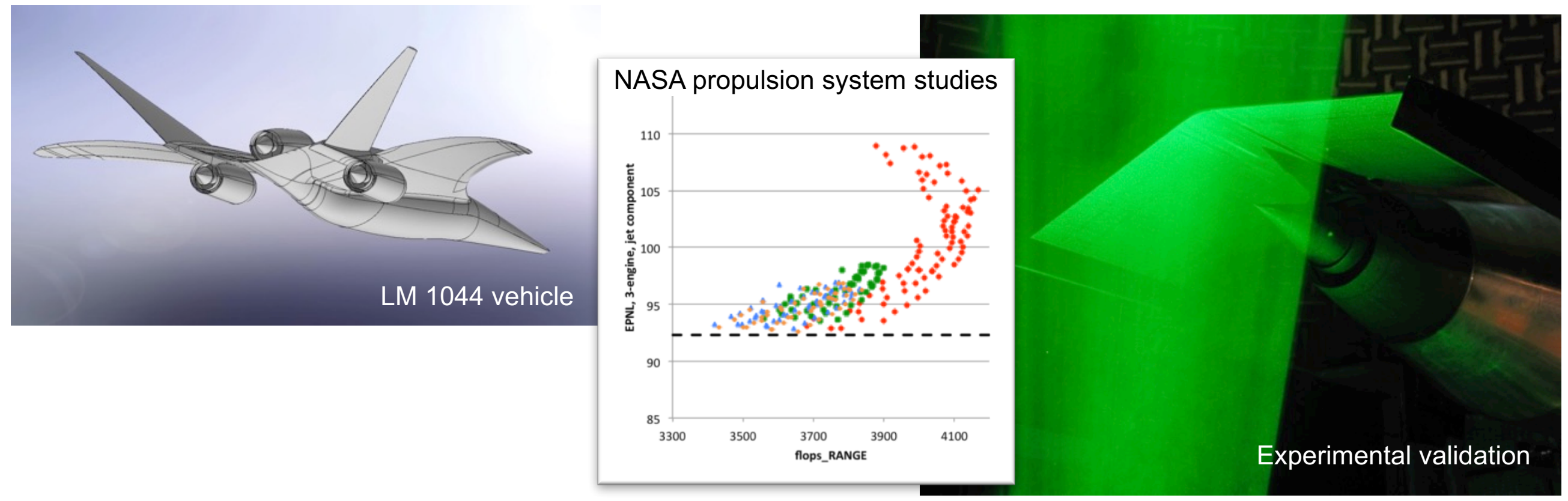


\section{Innovative Nozzle Concepts Explored}

2011

2012

2013

2014

2015

Mixer-Ejector

Twin Jet Shielding

3-Stream Offset
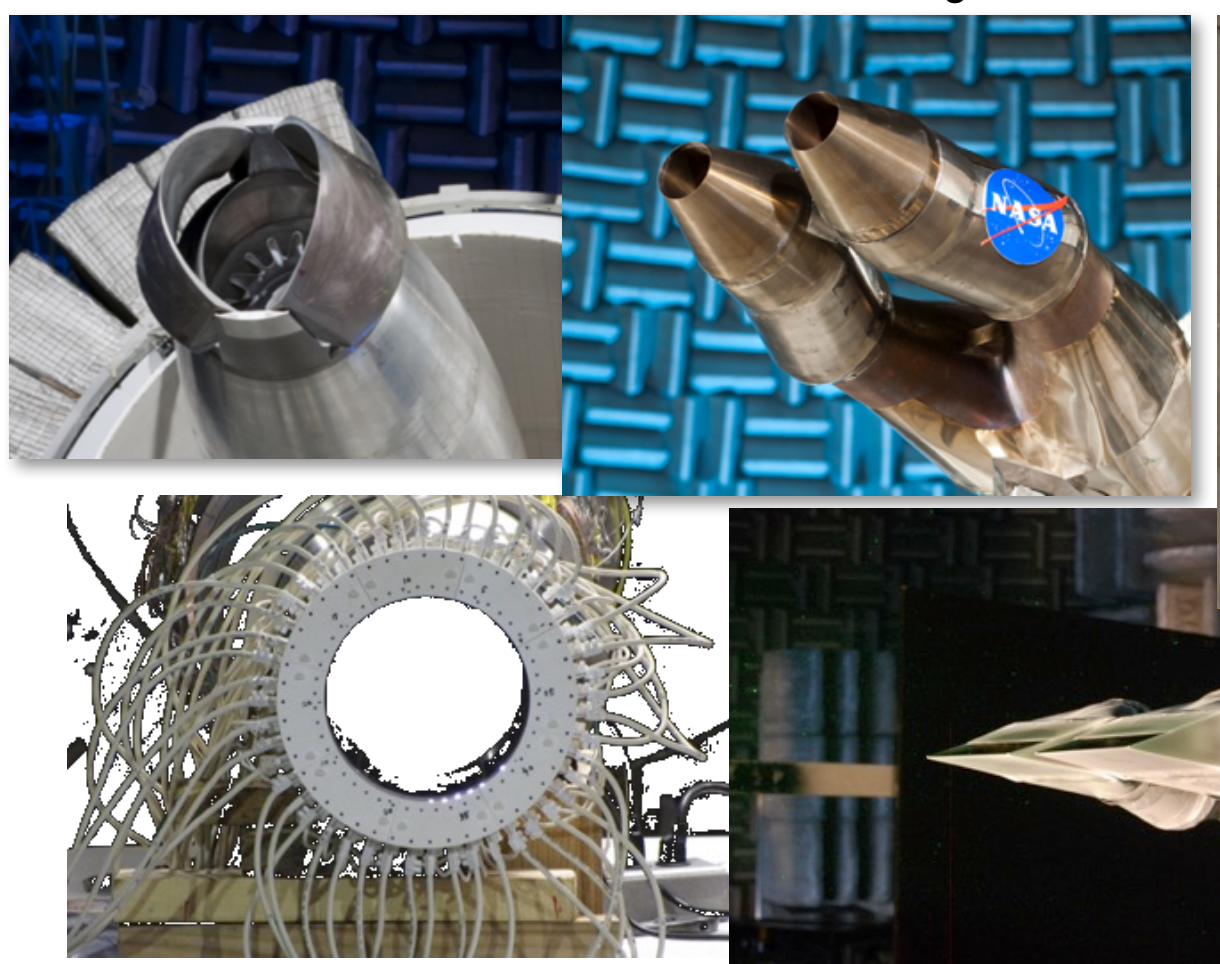

Plasma Excitation

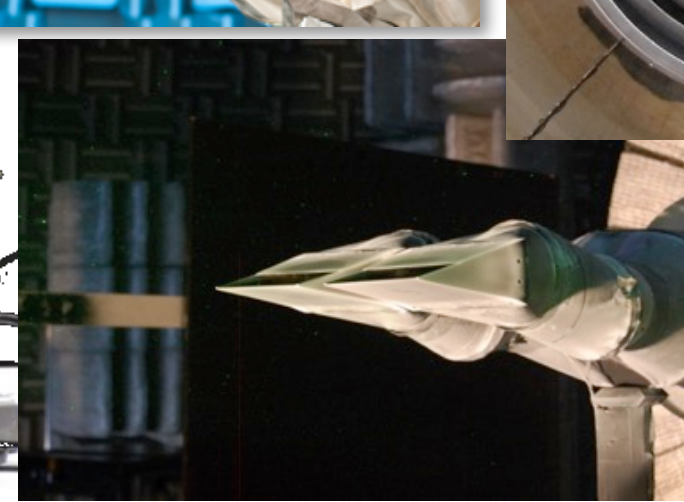

High Aspect Ratio

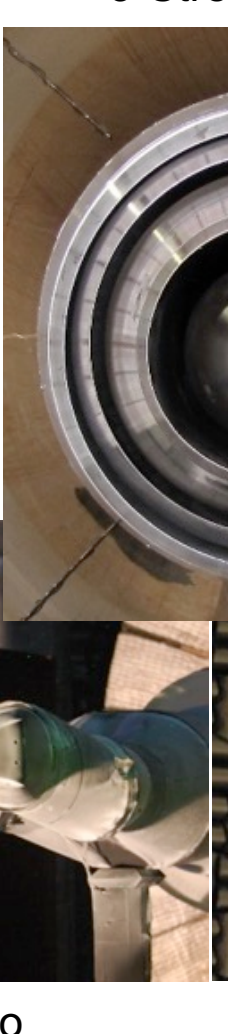

Split Velocity Profile

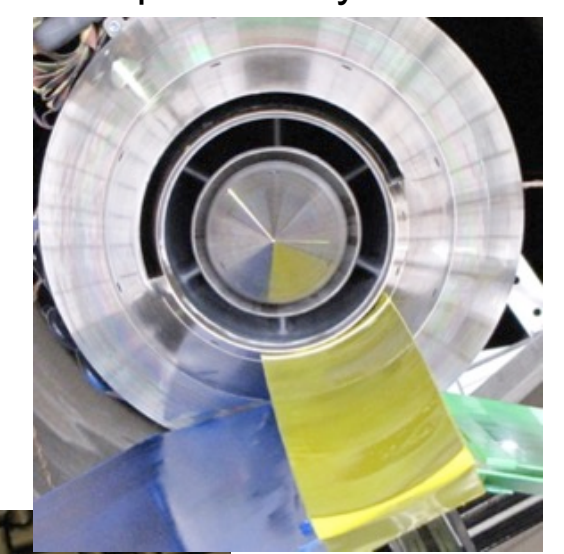

Acoustic benefits documented in databases for modeling used in design. 


\section{Broad Range of Noise Prediction Tools}

- NASA supported development of cutting edge jet noise prediction tools, from empirical models for system-level predictions, to large eddy simulations.

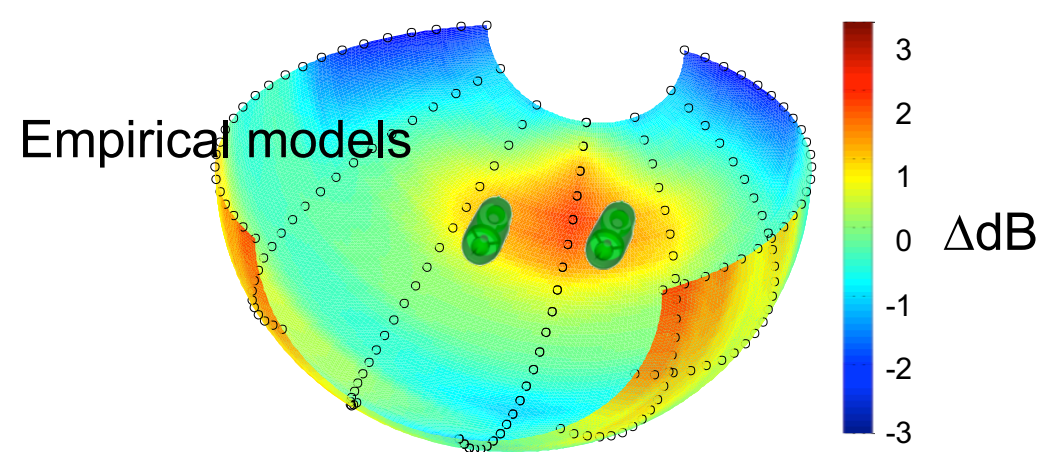

RANS-based noise prediction
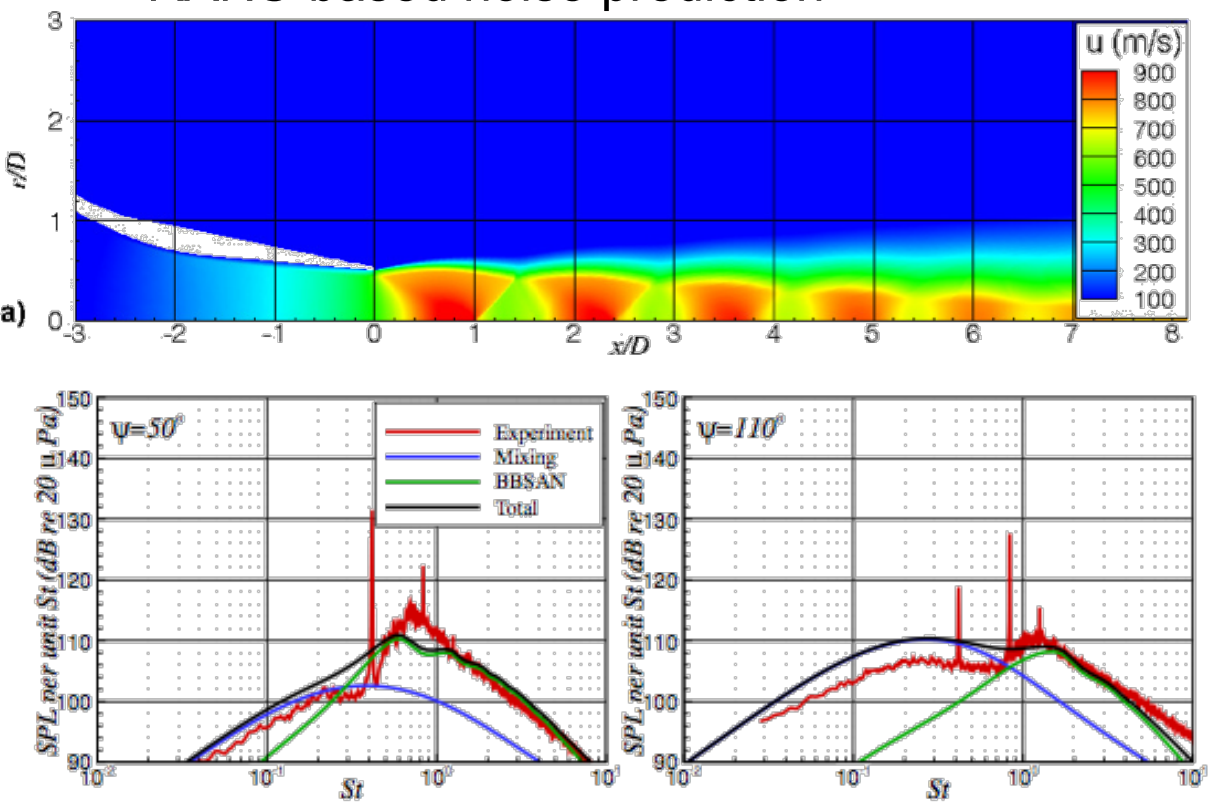

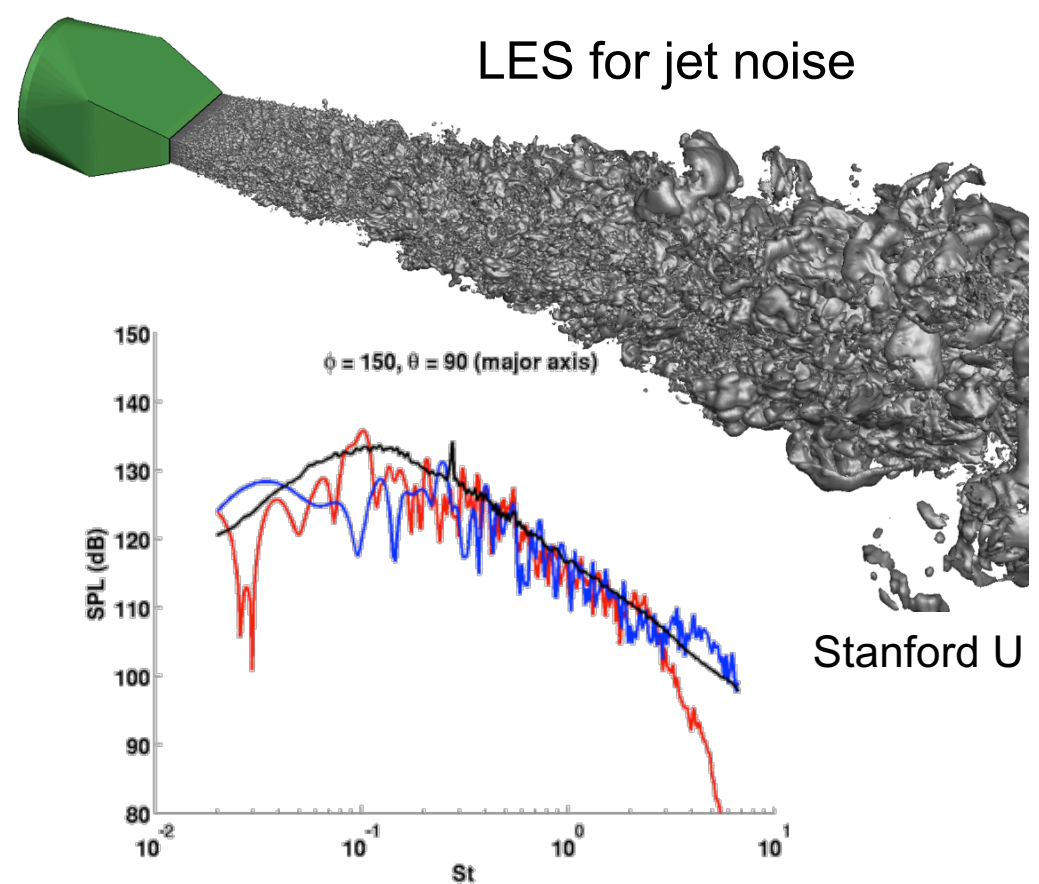




\section{Early exploration of Variable Cycle Engines (VCE)}

Noise vs range

- Exercise NPSS numerical model for VCE and mixed flow turbofan (MFTF) designs.

- Dominant design parameter for noise is Fan Pressure Ratio (FPR).

- At low FPR, both engines have large losses in range for noise benefit.

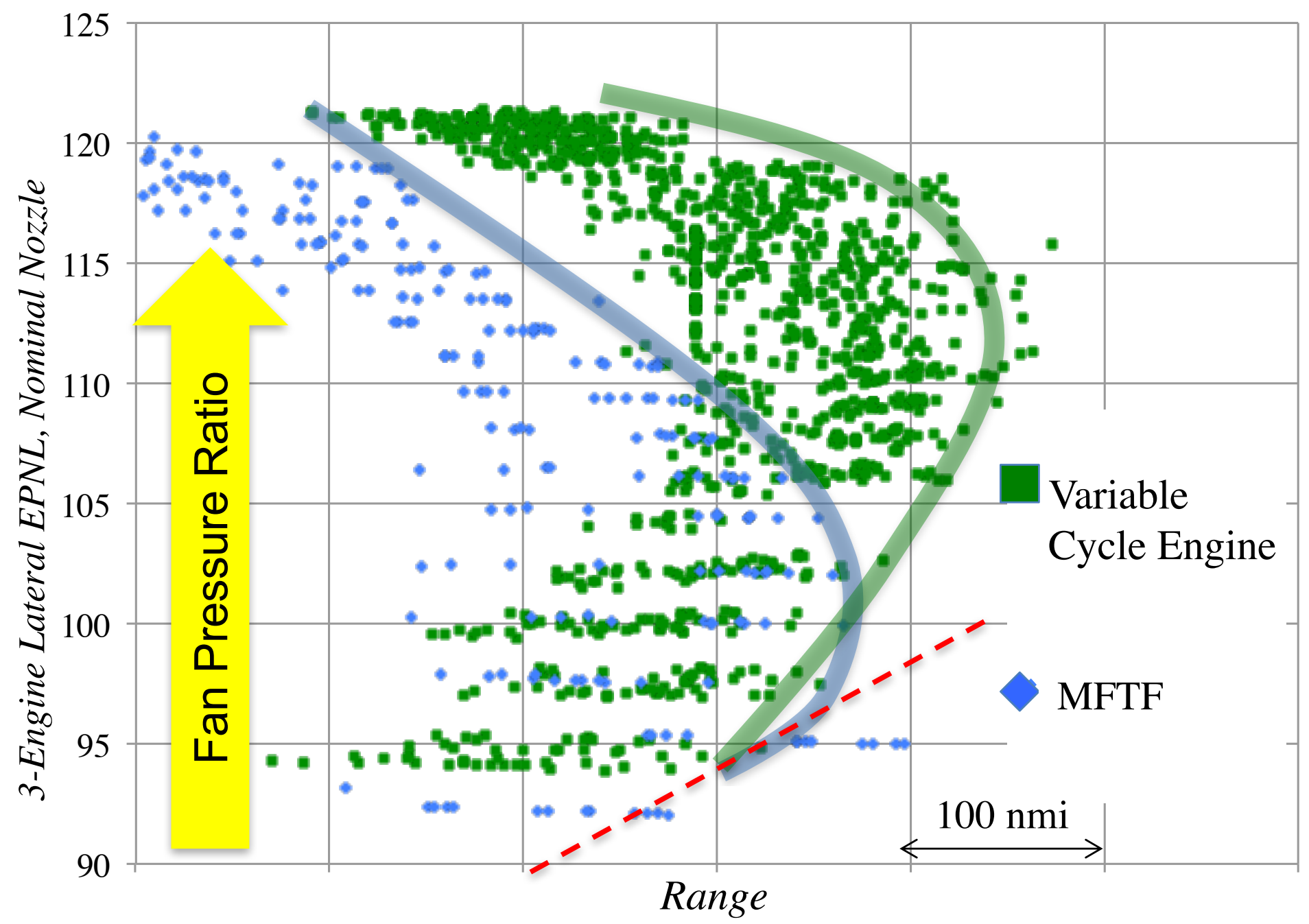




\section{Early exploration of Variable Cycle Engines (VCE)}

Noise vs Fan Diameter

- Fan diameter as surrogate for sonic boom.

- Lower FPR, larger engine diameter. Bad for boom, range.

- VCE engines have smaller diameter, more weight for given FPR.

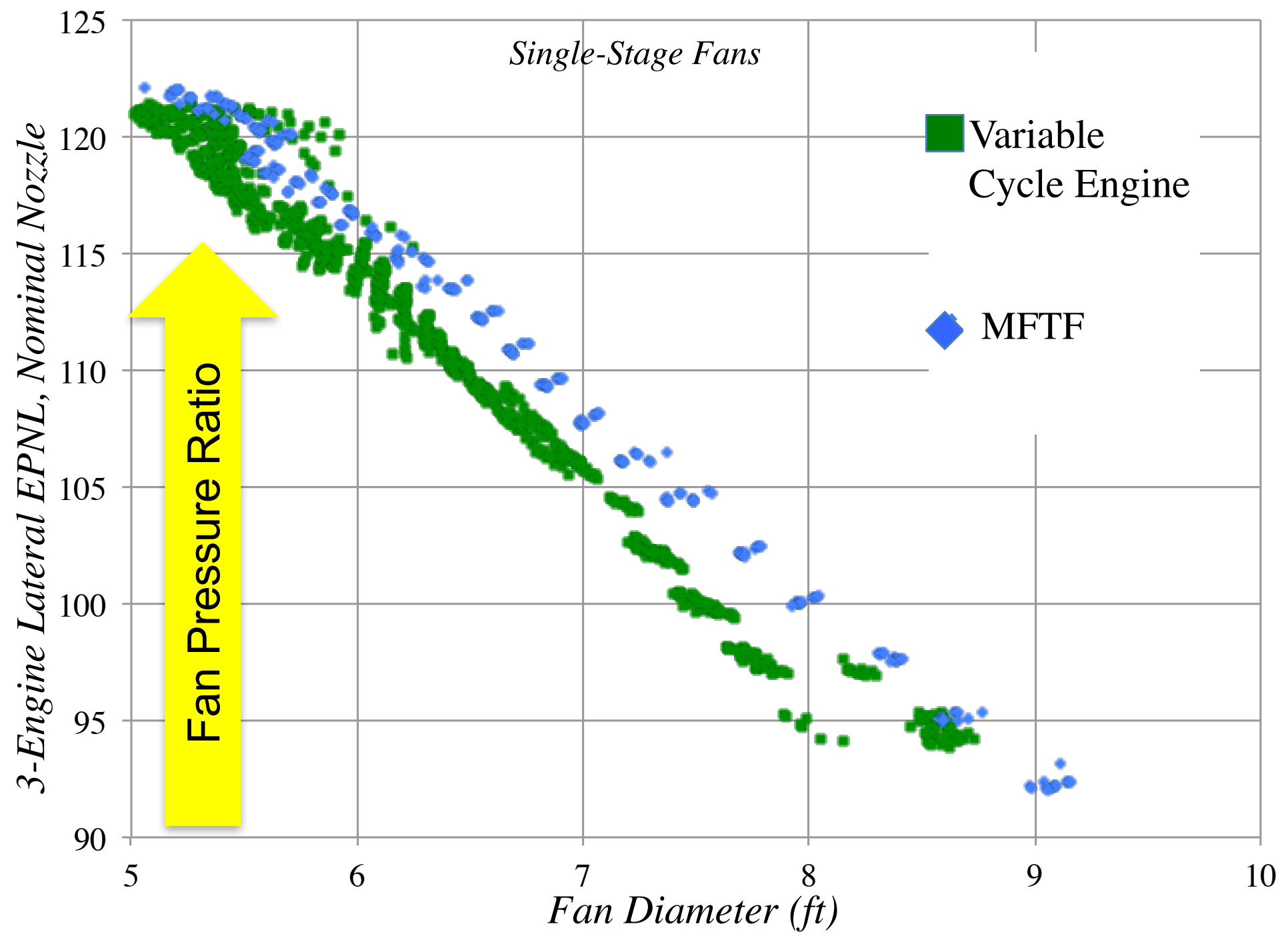




\section{Early exploration of Variable Cycle Engines (VCE)}

\section{Fan stage count}

- Increasing FPR produces smaller engines, more range.

- As FPR further increases, fan losses become prohibitive-add fan stages.

- As fan stages increase past 2, engine weight increases and max range suffers.

- Two-stage VCE significantly better range than two-stage MFTF.

- At FPRs where jet noise is tolerable, the mixed flow turbofan gives comparable or better range.

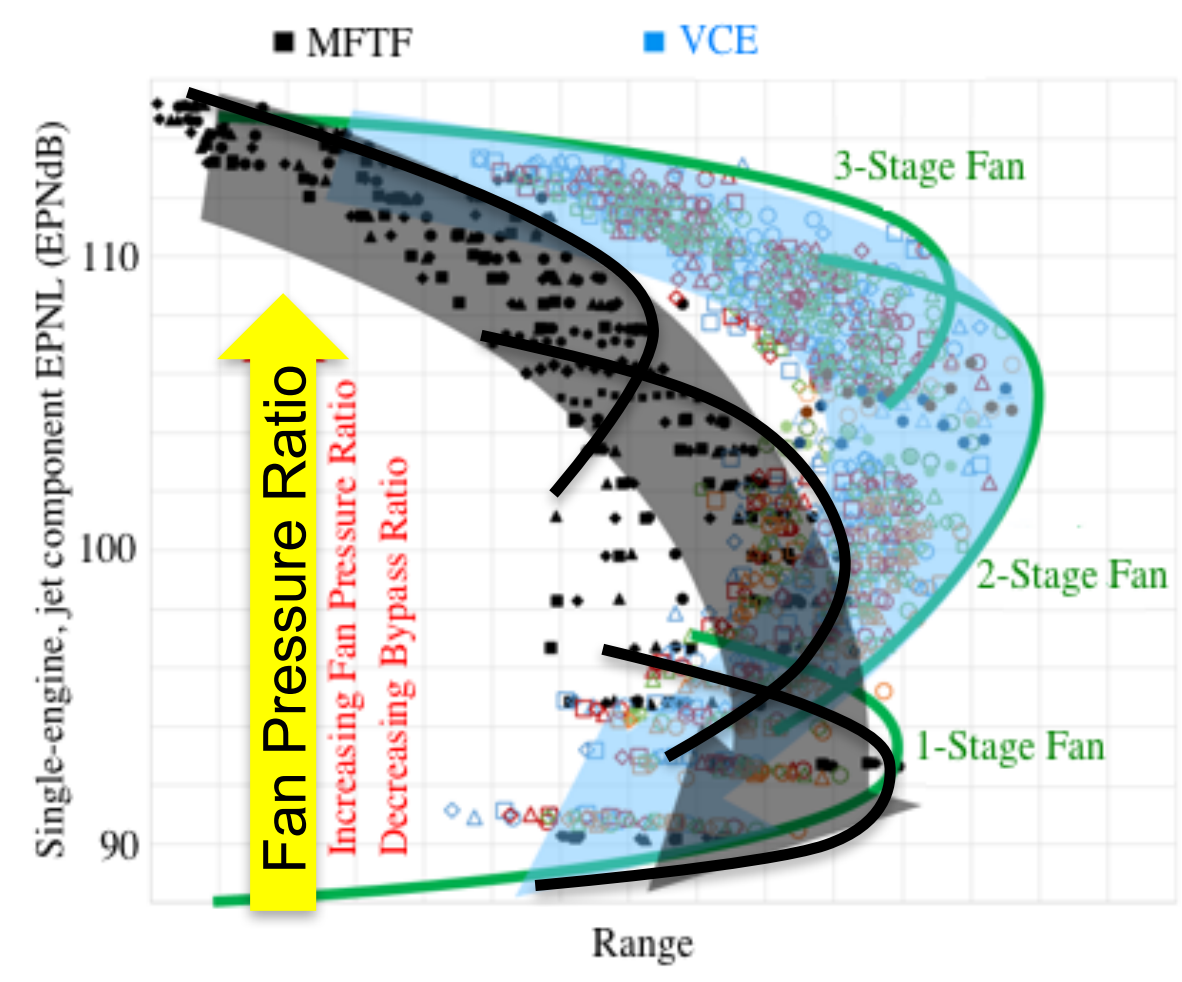




\section{Acoustic Impact of Nozzle type TSS models for noise of three-stream nozzles}

- Empirical noise models for various threestream nozzles developed from model-scale aeroacoustic tests.

- Applied as 'corrections' to basic Stone jet noise model in NASA's Aircraft Noise Prediction Program (ANOPP).

Three-stream nozzle types in TSS
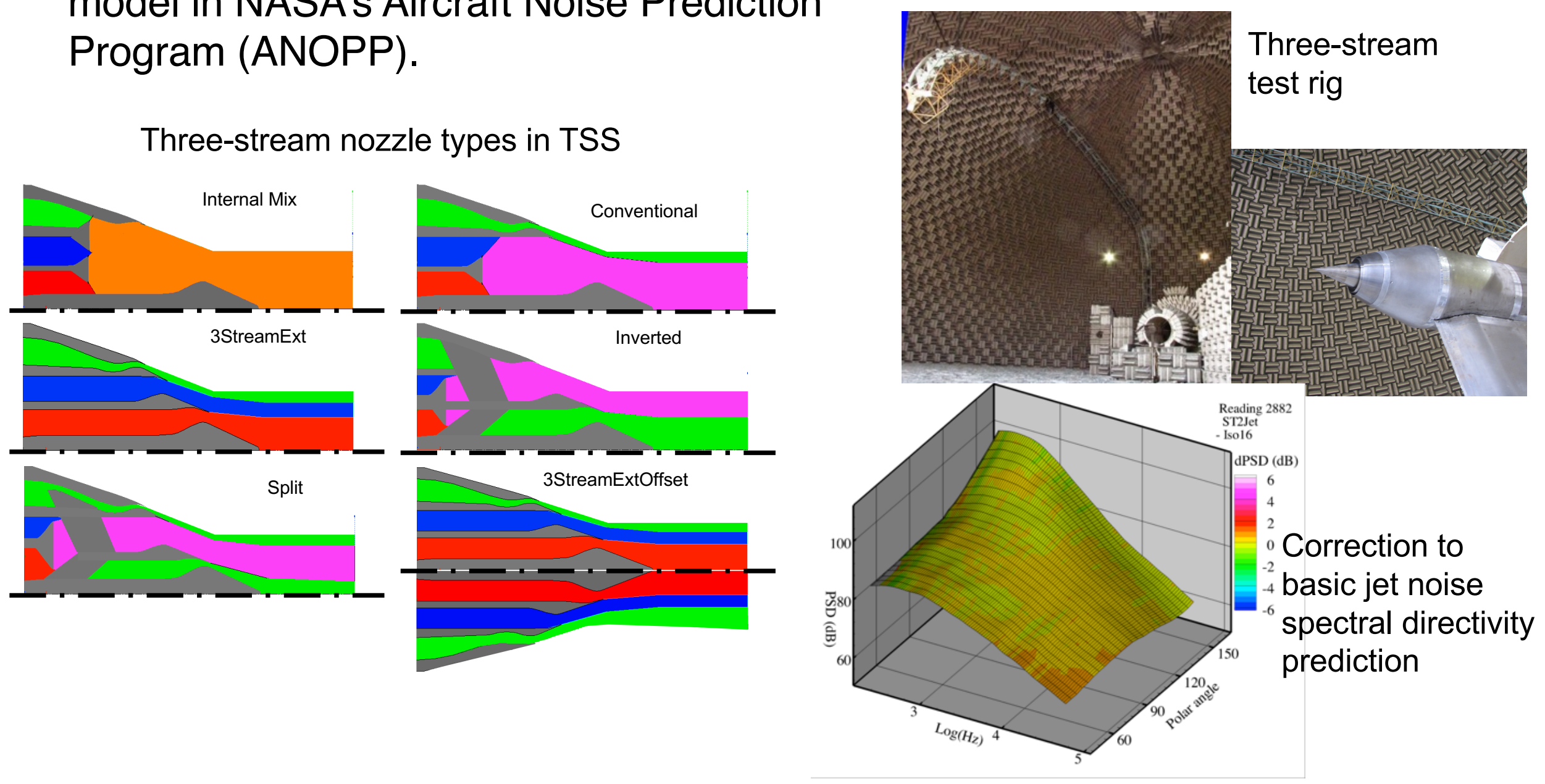


\section{Iso16 Test: Nozzle Type Validation Results}

- Noise prediction codes applied to VCE designs, tested on six nozzle types in isolation.

- Direct comparison of nozzles on same engine cycle.

- Results compared at spectral directivity and EPNL levels.

- Only separate flow nozzle significantly different.

- Most cases predicted within expected uncertainty of $\pm 1 \mathrm{EPNdB}$.
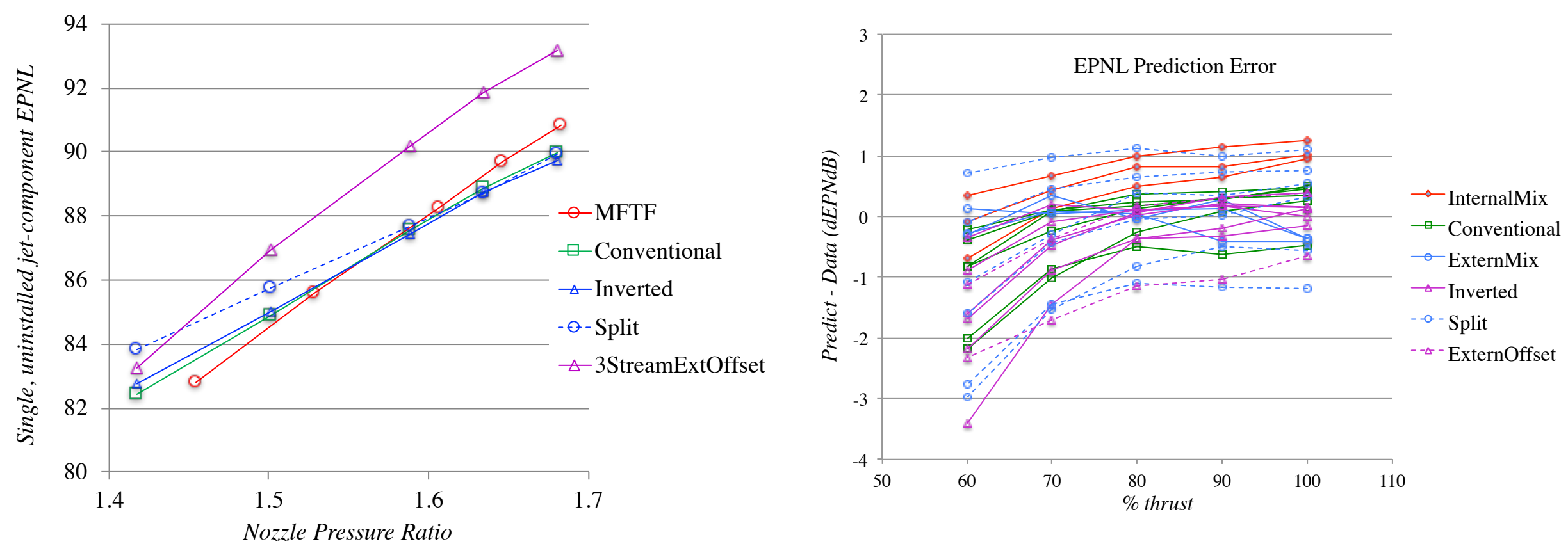


\section{JSI Tests: Effect of Installation on Jet Noise}

- Early simple experiments documented effect of shielding/reflection for simple round jet, and the addition of a trailing edge dipole source.

- Simple models developed for installation effect, but did not include impact of multiple stream nozzles, limited planform size, or flight.
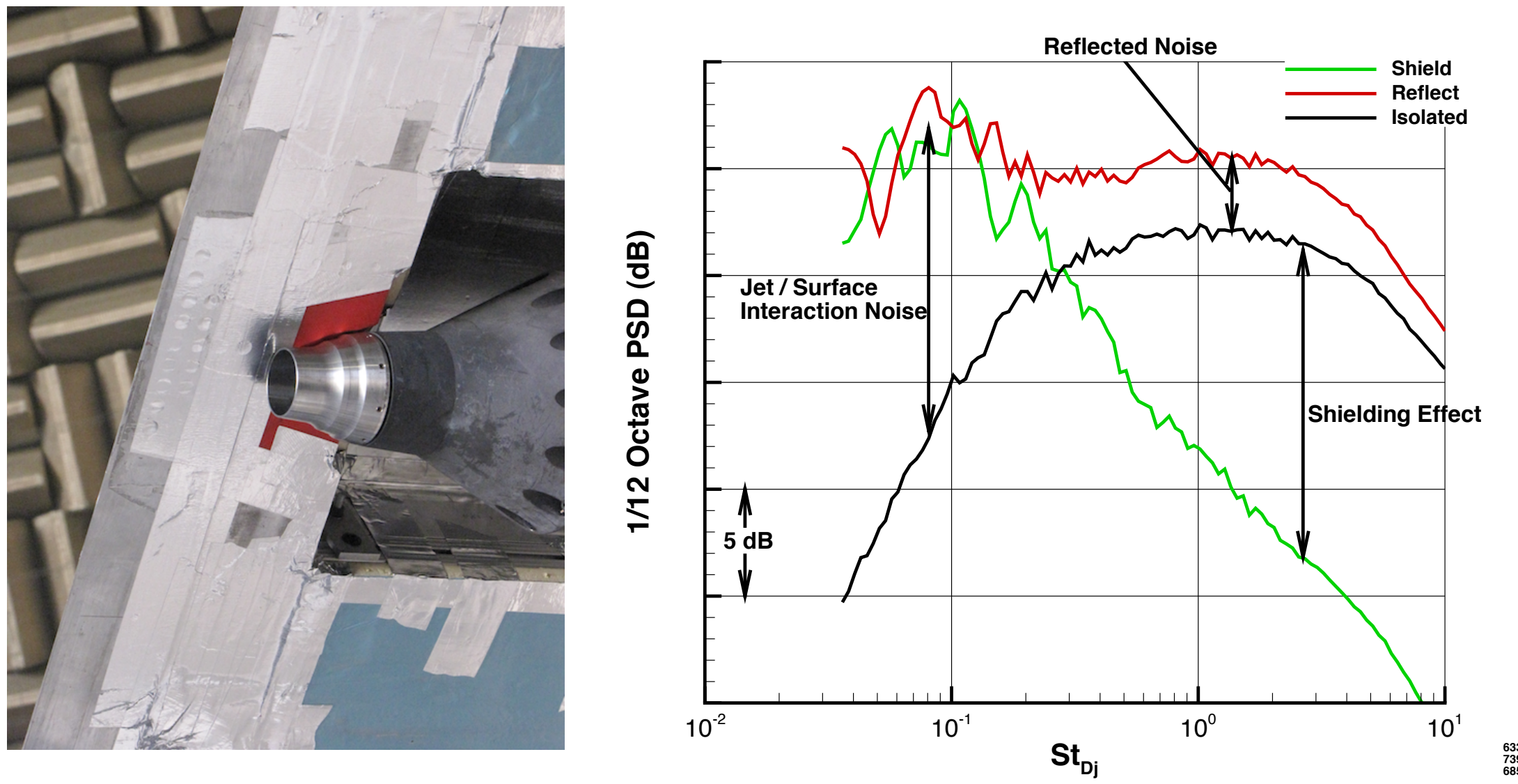


\section{JSI1044 Test: Installation Impact}

- Impact of installing engines underwing and overwing

- Static (no flight stream) test

- First jet-surface interaction test with multi-stream nozzles, realistic geometry
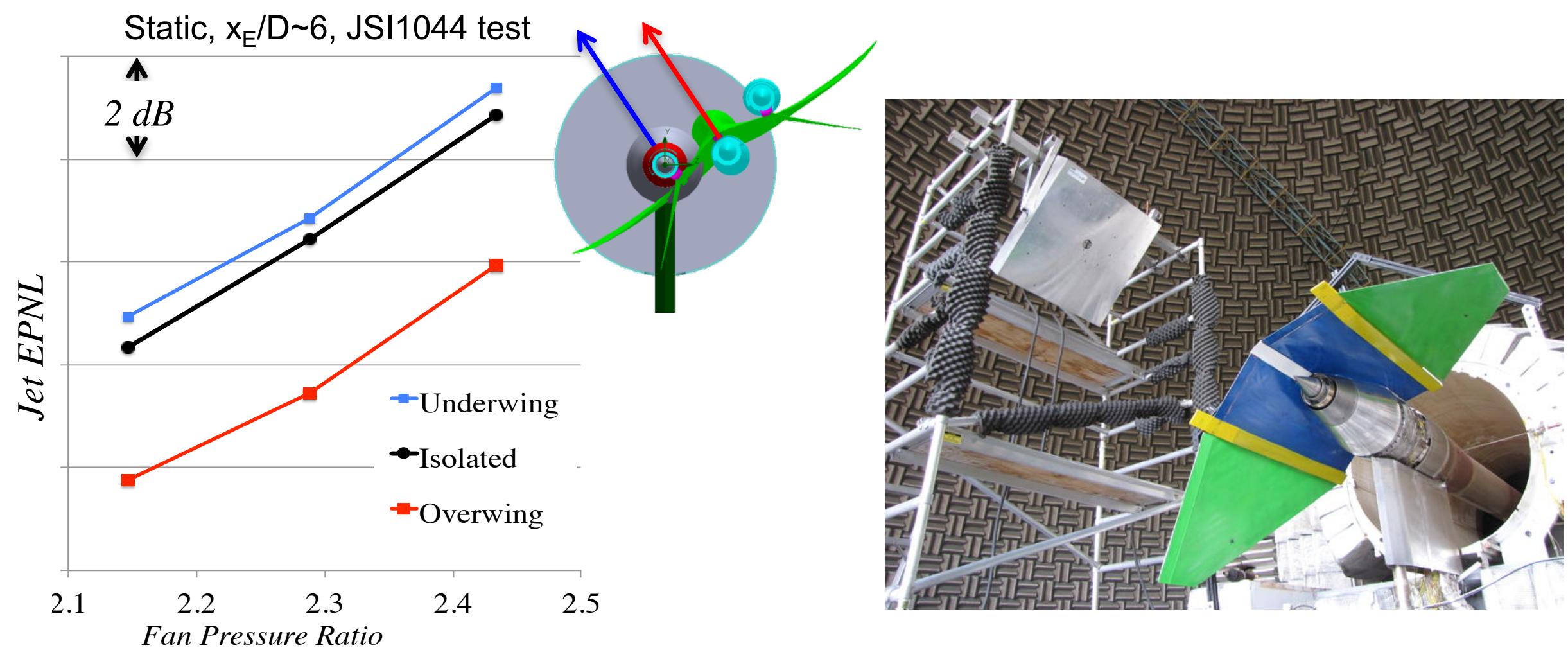

More shielding benefit possible from tailored nozzles_future tech development. 


\section{Engine/Nozzle Final Design for Validation}

- VCE coupled with LM1044 aerodynamic model and new noise prediction codes to predict mission range and Lateral EPNL.

- Designs that maximize range while meeting noise goal selected for demonstration

- Also selected designs requiring Programmed Lapse Rate (PLR) to demonstrate design sensitivities.

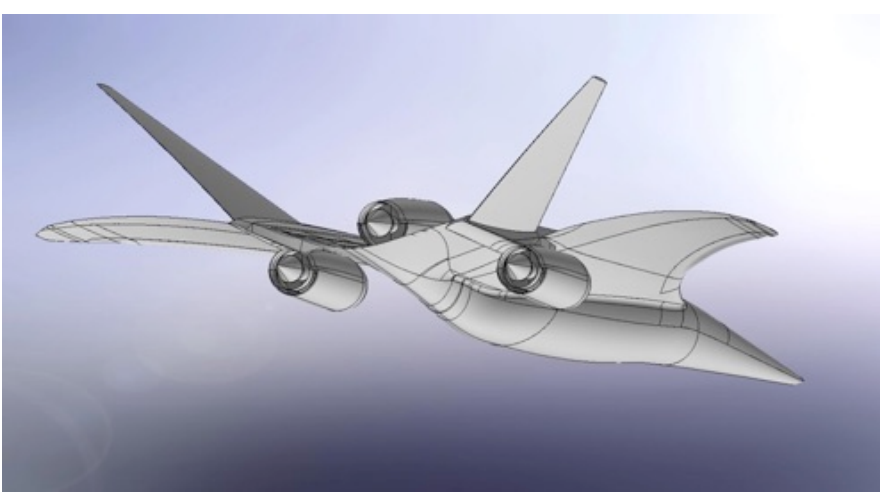

Conventional
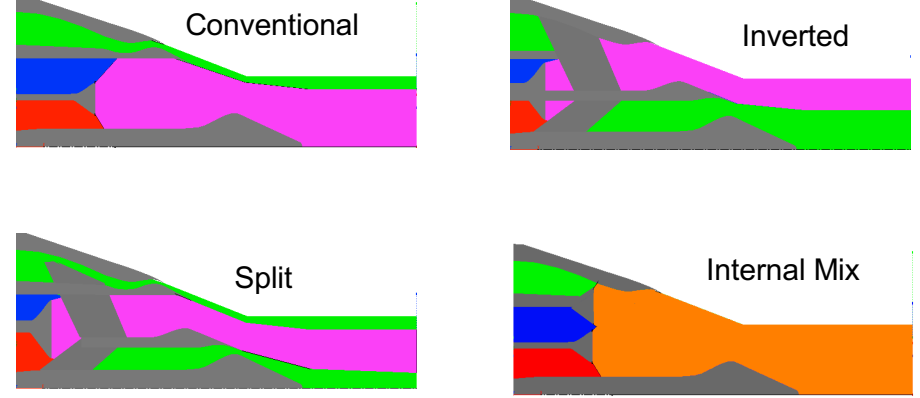

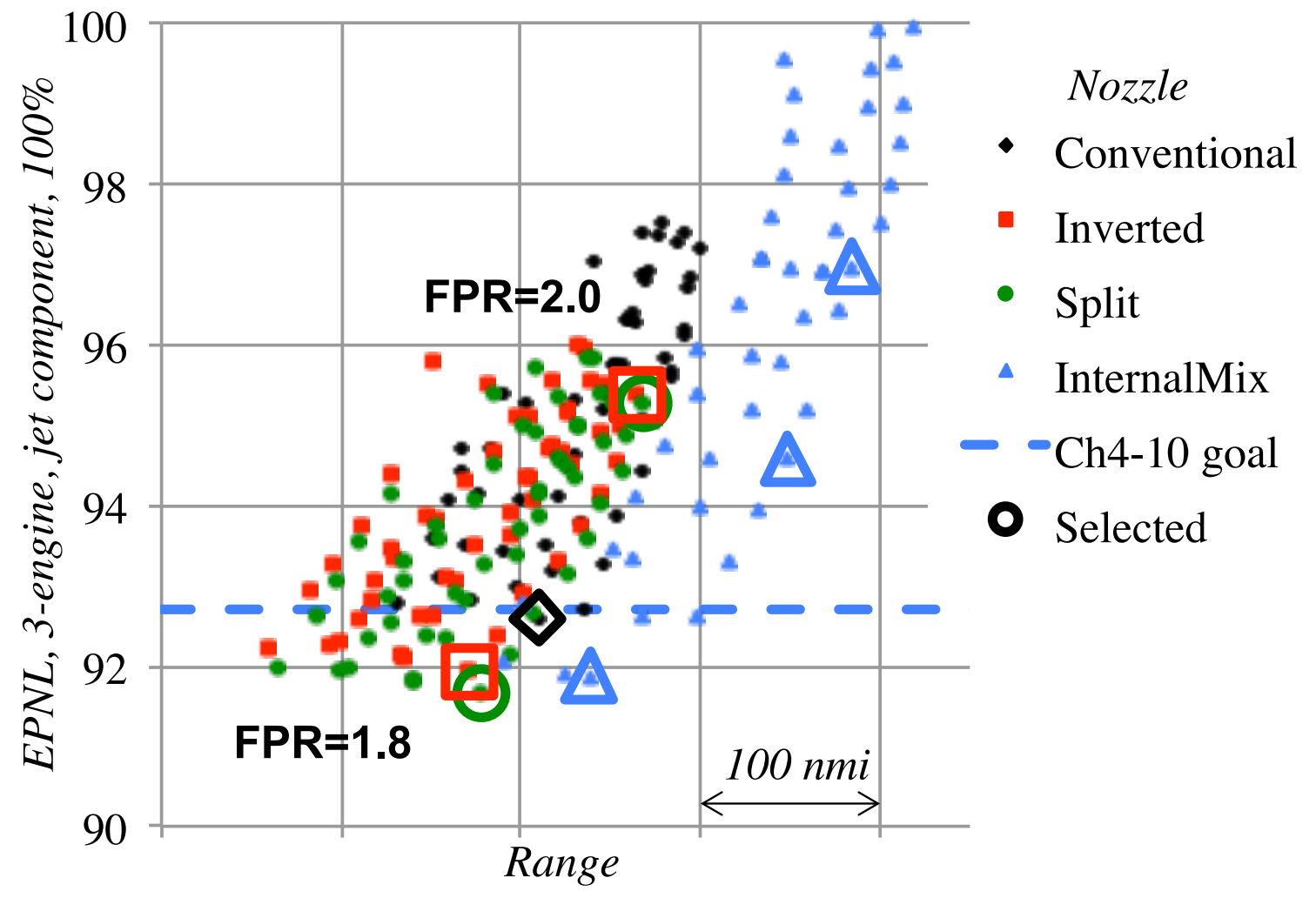




\section{JSI16 Integrated Propulsion Test}

- Ground test conducted on selected engine/nozzles to demonstrate that noise goal was met with integrated propulsion system.

- Test conducted at GRC Aero-Acoustic Propulsion Lab, an anechoic wind tunnel with engine simulator.

- Four nozzle types, seven engines, three installation variations, center topmounted and outboard underwing installations assessed at multiple flight speeds.

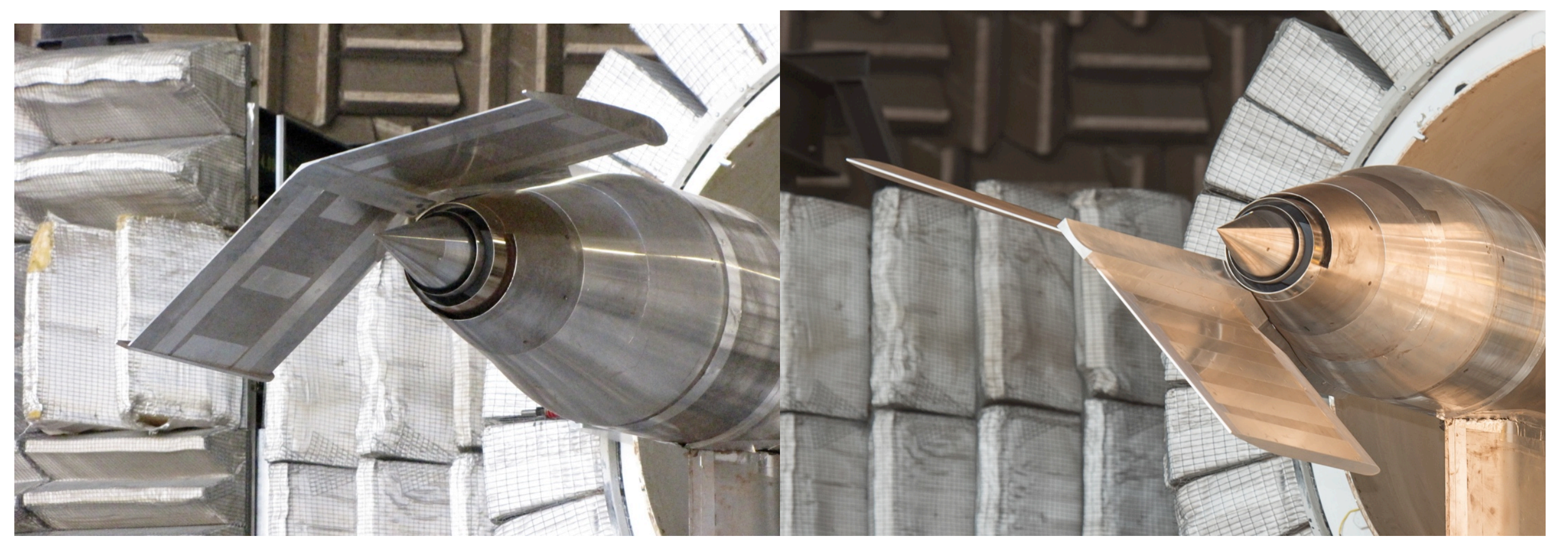




\section{Installation Effect-Mount Location}

- EPNL for each engine as seen by Lateral observer

- Grouped by engine/nozzle (plot) and cycle (color)
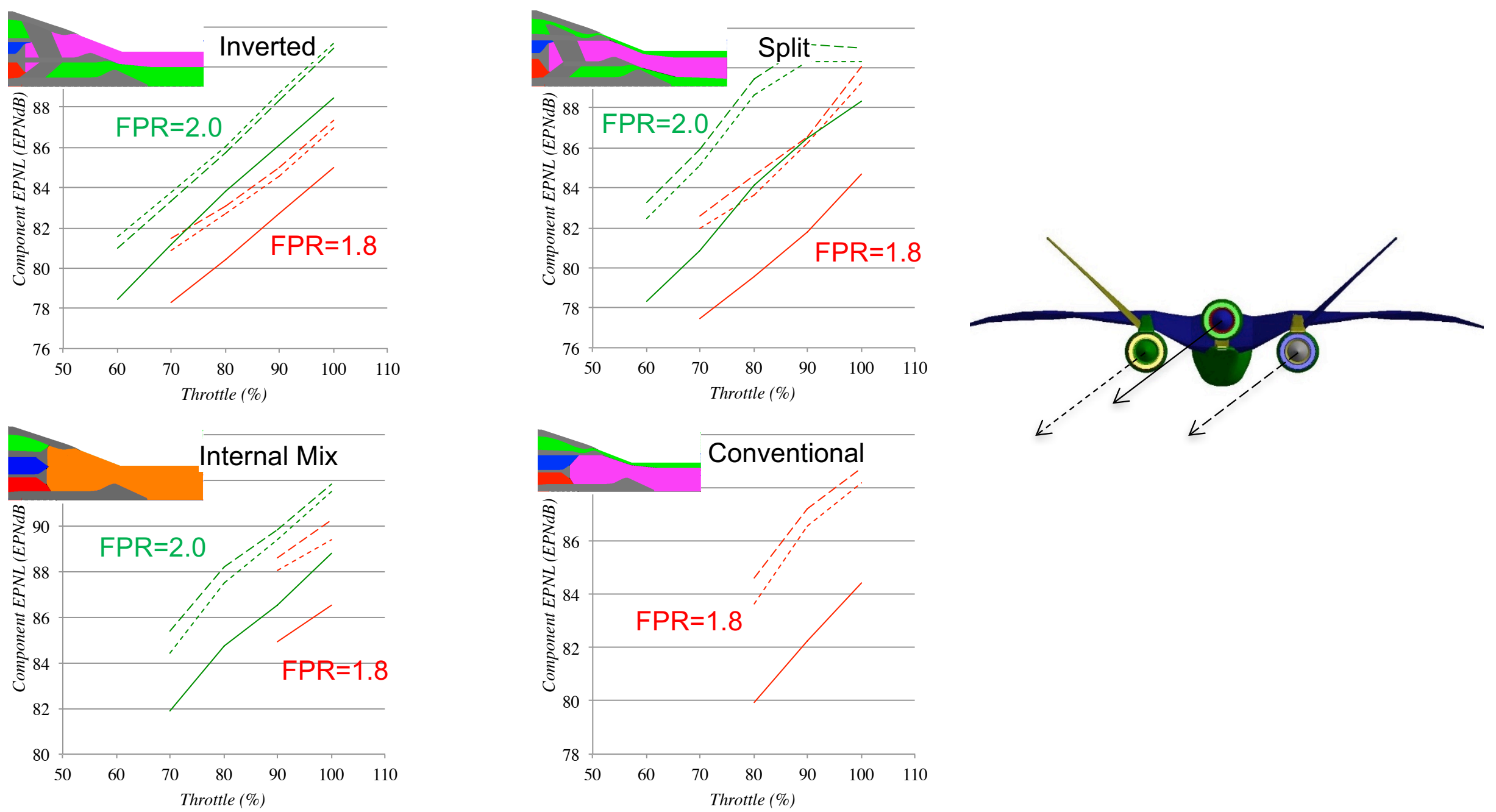


\section{Comparisons of Design Predictions and Data}

- JSI16 test Data plotted against design Predictions.

- Predictions match Data within $1 \mathrm{EPNdB}$, expected uncertainty of prediction method.

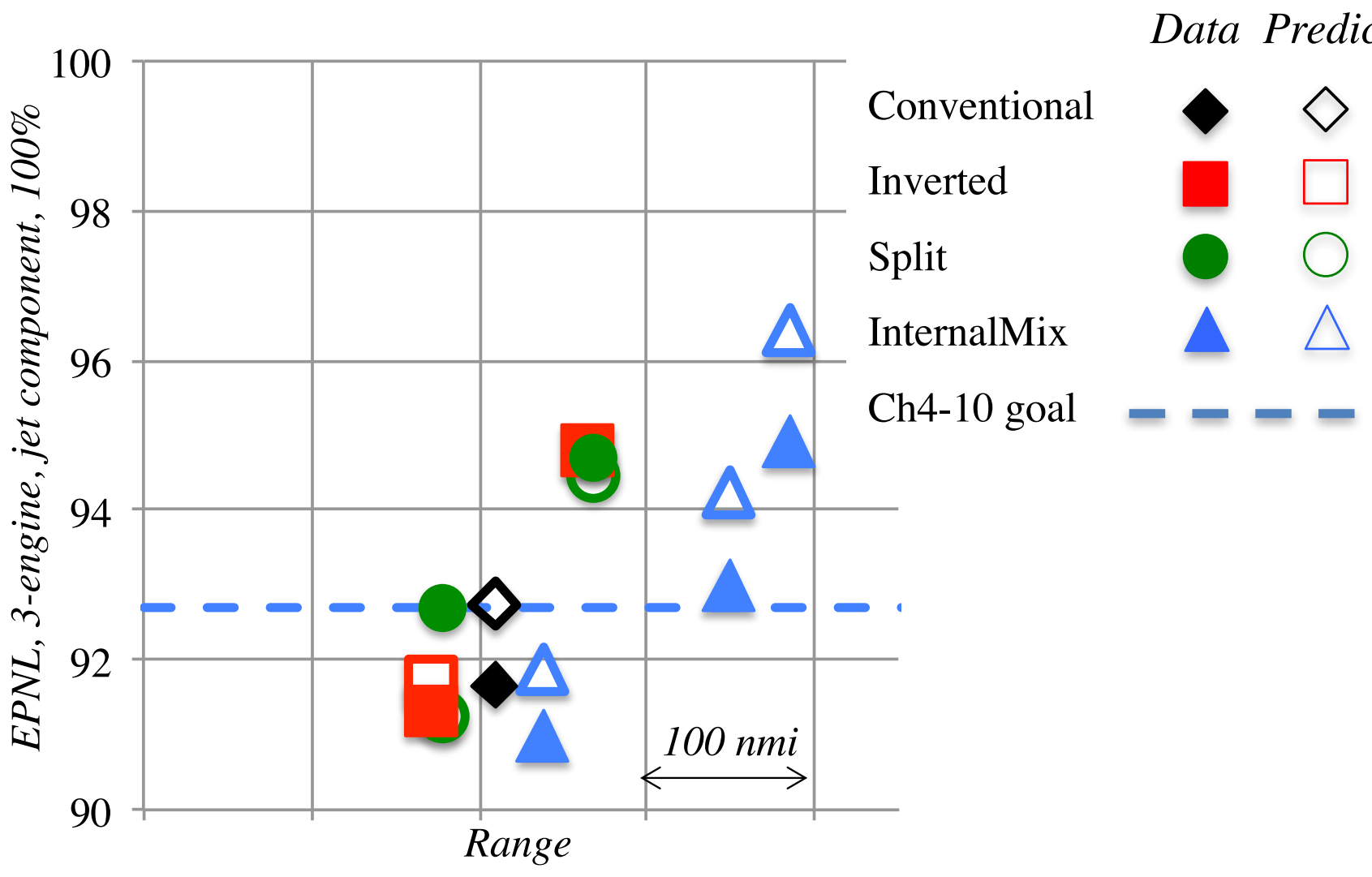

Significance: We have valid design tools for propulsion noise and know what must be done to meet airport noise regulations. This is not yet a closed design. 


\section{Summary}

- NASA-supported research has helped develop significantly improved jet noise prediction methods.

- New tools allow strong insight into physics of jet noise generation, and design of exhaust systems for noise.

- NASA-supported research has explored many low-noise nozzle concepts brought forward by noise community.

- Acoustic performance of concepts shown to reliably reduce noise captured in system-level tools and used to validate physics-based methods.

- Installation effects on exhaust noise explored and modeled.

- System-level propulsion studies used new noise tools to explore variable cycle engine concepts and find best designs that meet LTO noise requirements for a low-boom, 70 pax, supersonic aircraft.

- Study results for noise validated in model-scale acoustic test. 
- While formally the Low-Noise Propulsion Tech Challenge was successfully met, there were caveats.

- Although the fidelity of the range calculations were rough, the range of the acoustically successful designs were not satisfactory for commercial airliners.

- The original LM1044 aircraft did have a low boom signature, but the larger engines would have necessitated a redesign of the flow lines to regain low boom status.

- Significant lessons learned for future development of commercial supersonic aircraft

- Airport noise will be a problem even if the vehicle does not fly supersonic over land.

- Smaller aircraft than the 70PAX, M 1.6 LM1044 would be closer to subsonic fleet.

- VCEs not significantly better than mixed-flow turbofans given noise restrictions.

- Alternate operating procedures during landing and takeoff could help noise immensely.

- Installation effects are very significant and should be take advantage of.

- LTO noise will have to be a major design requirement for successful design

- Adequate noise levels cannot be obtained by nozzle design or engine cycle alone.

- Acoustic benefits from propulsion installation will be required. 


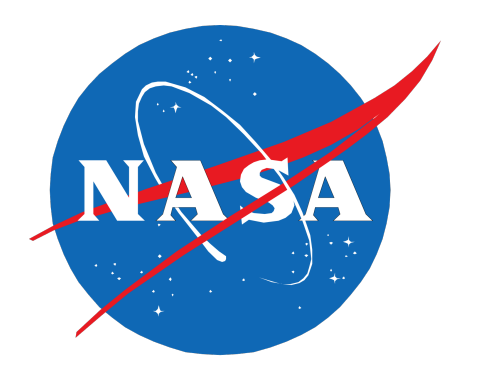

james.e.bridges@nasa.gov 